\title{
First-Principles Calculations of the Structural, Mechanical and Thermodynamics Properties of Cubic Zirconia
}

\author{
Ibrahim D. Muhammad1", Mokhtar Awang1, Othman Mamat', Zilati Bt Shaari \\ ${ }^{1}$ Mechanical Engineering Department, Universiti Teknologi Petronas, Seri Iskandar, Malaysia \\ ${ }^{2}$ Chemical Engineering Department, Universiti Teknologi Petronas, Seri Iskandar, Malaysia \\ Email: ${ }^{*}$ ibrahimuhd@gmail.com
}

Received 20 April 2014; revised 20 May 2014; accepted 20 June 2014

Copyright (C) 2014 by authors and Scientific Research Publishing Inc.

This work is licensed under the Creative Commons Attribution International License (CC BY).

http://creativecommons.org/licenses/by/4.0/

(c) (i) Open Access

\begin{abstract}
The structural, mechanical and thermodynamics properties of cubic zirconium oxide $\left(\mathrm{cZrO}_{2}\right)$ were investigated in this study using $a b$ initio or first-principles calculations. Density functional theory was used to optimize the crystal structure of $\mathrm{CZrO}_{2}$ and thereafter, simulations were conducted to predict the lattice parameters and elastic constants. The $\mathrm{Zr}-\mathrm{O}$ bond distance was calculated as 2.1763 Å with unit cell density of $6.4179 \mathrm{~g} / \mathrm{cm}^{3}$. The data obtained were used to determine Young's modulus, bulk modulus, Poisson's ratio and hardness of $\mathrm{CZrO}_{2}$ as $545.12 \mathrm{GPa}, 136.464 \mathrm{GPa}, 0.1898$ and $12.663\left(\mathrm{H}_{v}\right)$ respectively. The result indicates that $\mathrm{CZrO}_{2}$ is mechanically stable with thermodynamics properties of a refractory material having potential for structural and catalytic applications in various forms as a nanomaterial.
\end{abstract}

Keywords

Cubic Zirconium Oxide, First-Principles Calculation, CASTEP, Elastic Constants

\section{Introduction}

Recently, zirconium oxide in cubic polymorph has attracted interest due to its mechanical and thermal properties. These interests have resulted in the use of $\mathrm{CZrO}_{2}$ to various applications such as catalysts, fuel cells, oxygen sensors and others [1]-[4]. Thus $\mathrm{CZrO}_{2}$ has been synthesized at nanoscale in various forms. The sol-gel method

\footnotetext{
*Corresponding author.
}

How to cite this paper: Muhammad, I.D., Awang, M., Mamat, O. and Bt Shaari, Z. (2014) First-Principles Calculations of the Structural, Mechanical and Thermodynamics Properties of Cubic Zirconia. World Journal of Nano Science and Engineering, 4, 97-103. http://dx.doi.org/10.4236/wjnse.2014.42013 
was used to produce $\mathrm{ZrO}_{2}$ nanoparticles with fairly uniform dimension ranging from $50 \mathrm{~nm}$ to $90 \mathrm{~nm}$ [5]. $\mathrm{ZrO}_{2}$ nanosheets with thickness in the range of 3.2 - $4.2 \mathrm{~nm}$ were produced through bottom-up synthesis by impregnation of graphene oxide in cyclohexane containing Zr-based alkoxides [6]. Also, $\mathrm{ZrO}_{2}$ nanotubes have been prepared via several methods such as direct anodization, template-assisted depositions and hydrothermal treatments [2]; the nanotubes obtained have different inner and outer diameters, thicknesses and lengths.

For efficient and cost-effective applications of $\mathrm{cZrO}_{2}$, its structural and mechanical properties are required at molecular and atomic scale. But due to complexity and high cost of equipment, only limited experiments have been conducted to characterize required properties of $\mathrm{cZrO}_{2}$ at nanoscale and/or atomic level [2] [4]. This led to computational modeling and simulation of various properties of $\mathrm{cZrO}_{2}$ based on atomistic and continuum approaches [1] [2]. However, most of the simulations already conducted are limited to properties such as electronic structures, phonon dispersion, surface adsorption and diffusion [7]-[13] with limited emphasis on structural and mechanical properties.

Therefore, in this study the first-principles calculations are utilized to numerically predict the structural characteristics, mechanical properties and thermodynamic properties of $\mathrm{cZrO}_{2}$. The values obtained are used to analyze the structural stability of $\mathrm{cZrO}_{2}$ and compared available data for further simulation(s).

\section{Computational Methods}

The 3D structure of $\mathrm{CZrO}_{2}$ was modeled from available data [2] using the surface builder tools of the Material Studio software [14]. The crystal structure ofc $\mathrm{ZrO}_{2}$ was optimized geometrically in order to obtain initial lattice parameters and density based on density function theory (DFT) as implemented in Cambridge Sequential Total Energy Package (CASTEP) code [15]. In this calculation, the Generalized Gradient Approximation (GGA) having Burke-ErnZerhof Potential (PBE) for solids was used [13]. To obtain accurate structures, the calculations were conducted in the irreducible Brillouin zone with $8 \times 8 \times 8 \mathrm{k}$ point mesh Monk horst-Pack scheme [16]. In order to obtain plane wave expansions, a kinetic energy cut-off value of $380 \mathrm{eV}$ was used. Thereafter the Broyden- Fletcher-Goldfarb-Shannon (BFGS) optimization method was used with fixed basis quality to obtain the symmetric crystal structure of $\mathrm{cZrO}_{2}$. During the optimization process, the total energy was designed to converge to $5 \times 10^{-6} \mathrm{eV}$ and the force per atom diminished to $0.002 \mathrm{eV} / \AA$. The optimized structure of $\mathrm{cZrO}_{2}$ was then simulated to obtain required mechanical and thermodynamics properties.

\section{Results and Discussion}

\subsection{Crystal Structure}

The bulk crystal structure of $\mathrm{CZrO}_{2}$ belongs to the $F m$-3m space [4] [9] and is modeled in various forms as seen in Figure 1. The geometric structure has influence on the properties of the material even at nanoscale [2]. After optimization, all the lattice parameters were recorded and compared with values obtained from other simulations and experiments as summarized in Table 1. It was observed that the deviation of the lattice parameters is less than $3 \%$ from the experimental values, which may be due to the approximation method used during optimization.

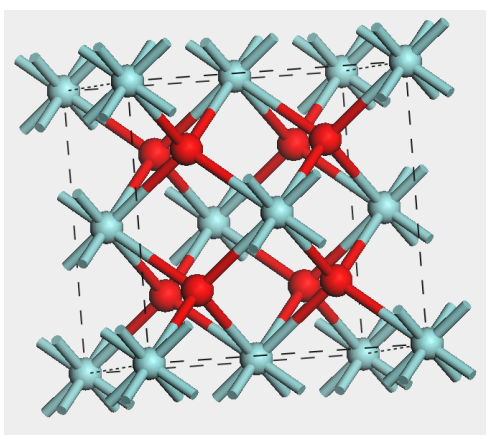

(a)

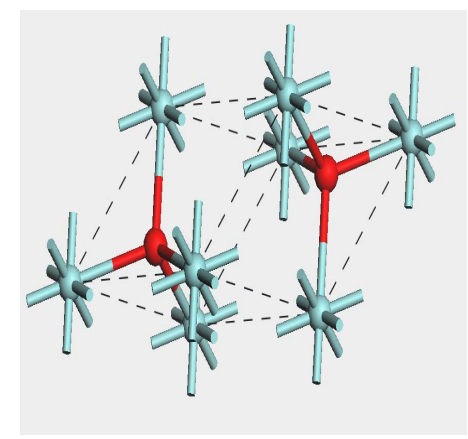

(b)

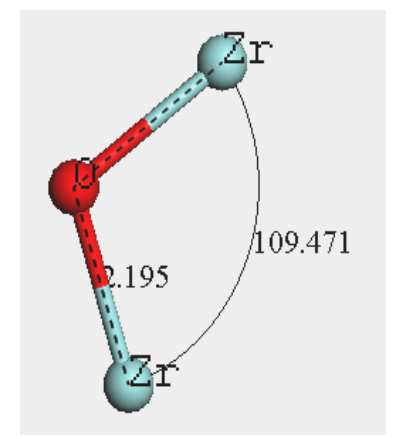

(c)

Figure 1. Crystal structure of $\mathrm{cZrO}_{2}$ in various forms: (a) Unit Cell; (b) Primitive Cell; (c) $\mathrm{Zr}-\mathrm{O}$ Bond $\left(\mathrm{O}_{2}\right.$ and $\mathrm{Zr}$ atoms are represented by red and light blue balls respectively). 
Table 1. Lattice parameters of optimized $\mathrm{cZrO}_{2}$.

\begin{tabular}{cccc}
\hline & \multicolumn{3}{c}{ Simulations } \\
Parameters & Present Study & Other(s) & Experimental \\
\cline { 2 - 4 } & 3.55381 & $3.58031[4]$ & $3.6012[17]$ \\
$\mathrm{a}=\mathrm{b}=\mathrm{c}(\AA)$ & 2.1763 & $2.19537[2]$ & $2.205[5]$ \\
Bond Length $(\mathrm{Zr}-\mathrm{O}), \AA$ & 31.8808 & $32.5850[3]$ & $32.723[17]$ \\
Volume $\left(\AA^{3}\right)$ & 6.41791 & $6.081[18]$ & $6.151[18]$ \\
Density $\left(\mathrm{g} / \mathrm{cm}^{3}\right)$ & & \\
\hline
\end{tabular}

\subsection{Mechanical Properties}

The mechanical properties of $\mathrm{cZrO}_{2}$ are based on the elastic constants of the crystal which indicates response to external forces. There are six components of stress and a corresponding six components of strain for the general 3-D case. Thus, Hooke's law may be expressed as:

$$
\begin{aligned}
\sigma_{i} & =C_{i j} \varepsilon_{j} \\
\varepsilon_{i} & =S_{i j} \sigma_{j}
\end{aligned}
$$

where $C=$ stiffness or elastic constant, $S=$ compliance, $\sigma=$ stress and $\varepsilon=$ strain. In matrix format, the stressstrain relation showing the $36(6 \times 6)$ independent components of stiffness can be represented as [3]:

$$
\left(\begin{array}{l}
\sigma_{1} \\
\sigma_{2} \\
\sigma_{3} \\
\sigma_{4} \\
\sigma_{5} \\
\sigma_{6}
\end{array}\right)=\left(\begin{array}{llllll}
C_{11} & C_{12} & C_{13} & C_{14} & C_{15} & C_{16} \\
C_{21} & C_{22} & C_{23} & C_{24} & C_{25} & C_{26} \\
C_{31} & C_{32} & C_{33} & C_{34} & C_{35} & C_{36} \\
C_{41} & C_{42} & C_{43} & C_{44} & C_{45} & C_{46} \\
C_{51} & C_{52} & C_{53} & C_{54} & C_{55} & C_{56} \\
C_{61} & C_{62} & C_{63} & C_{64} & C_{65} & C_{66}
\end{array}\right)\left(\begin{array}{c}
\varepsilon_{1} \\
\varepsilon_{2} \\
\varepsilon_{3} \\
\varepsilon_{4} \\
\varepsilon_{5} \\
\varepsilon_{6}
\end{array}\right)
$$

The number of independent elastic constants in $\mathrm{cZrO}_{2}$ is three (3), i.e. $\mathrm{C}_{11}, \mathrm{C}_{12}$ and $\mathrm{C}_{44}$ which are computed as 596.33, 137.04 and 74.34 GPa respectively. Also the bulk modulus (B) was calculated as 290.134 GPa using the Voigt model, which is comparable to experimental value [17].

With reference to Born-Huang's lattice dynamic theory [19], the mechanical stability of a cubic system is based on the conditions expressed in Equations (4) and (5).

$$
\begin{gathered}
C_{11}>0, C_{44}>0, C_{11}-C_{12}>0, C_{11}+2 C_{12}>0 \\
C_{12}<B<C_{11}
\end{gathered}
$$

Based on conditions outlined in Equations (4) and (5), the structure is mechanically stable due to lattice parameters and orientation of the crystal. The stability will make polycrystalline $\mathrm{CZrO}_{2}$ less vulnerable to generating micro cracks [19].

For $\mathrm{CZrO}_{2}$, computed Young's modulus (E) is $545.12 \mathrm{GPa}$, shear modulus (G) based on Voigh model is 136.464 GPa and the Lame modulus based on Reus model is $222.195 \mathrm{GPa}$. The G/B ratio indicates the ductility or brittleness of a material [19] and was found out to be 0.469 , which indicates that $\mathrm{CZrO}_{2}$ ionic and brittle. This is becausefor covalent and ionic materials, the typical relations between bulk modulus and shear modulus are as $\mathrm{G} \approx 1.1 \mathrm{~B}$ and $\mathrm{G} \approx 0.6 \mathrm{~B}$, respectively [20]. The Poisson's ratio $(v)$ of $\mathrm{cZrO}_{2}$ vary from 0.14 to 0.189 , which indicates less metallic and ionic character in the $\mathrm{Zr}-\mathrm{O}$ bond.

In crystals, hardness quantifies the resistance to deformation and may be predicted using microscopic models [17]. The hardness (Hv) of $\mathrm{cZrO}_{2}$ is determined using a semi-empirical equation defined as follows [21] [22]:

$$
H_{v}=0.92 K^{1.137} G^{0.708}, K=G / B
$$

The obtained hardness (Vickers number) for $\mathrm{CZrO}_{2}$ is 12.663 , which is consistent with the chemical bonding and elastic modulus as analyzed above and in similar other studies [19]-[22]. 


\subsection{Thermodynamic Properties}

The thermodynamic properties of a solid have direct relevance to its phonon characteristics as it indicates the quantum of elastic strain energy [19]. Hence, the phonon dispersion curve of a material elucidates the thermal properties based on the concept of lattice vibrations and interpretation of lattice dynamics [15]. Using the method of linear response with $0.051 / \AA$ q-vector grid spacing, the phonon dispersion curves (PDC) for $\mathrm{CZrO}_{2}$ was generated as shown in Figure 2. The lower section of G-X direction indicates higher longitudinal energy while most of the branches in the $\mathrm{X}-\mathrm{K}$ direction converge as non-degenerate, thus leading to the expected nine branches for a typical cubic structure [19].

With the aid of data from the phonon dispersion curves (PDC), quasi-harmonic approximation was used to evaluate some temperature dependent properties of $\mathrm{cZrO}_{2}$ such as entropy, enthalpy, free energy and Debye temperature as illustrated in Figure 3 and Figure 4. From Figure 3, the zero-point energy was computed to be $0.20385 \mathrm{eV}$ and the heat capacity per unit cell had a maximum value of $16.8957 \mathrm{cal} / \mathrm{K}(0.07069 \mathrm{~kJ} / \mathrm{K})$ at 992.25 $\mathrm{K}$. Debye temperature gives an approximation for the low temperature heat capacity of insulating crystalline solids. The maximum Debye temperature for $\mathrm{CZrO}_{2}$ was found to be $946 \mathrm{~K}$ which is similar to $963 \mathrm{~K}$ for $\mathrm{Y}_{2} \mathrm{O}_{3}$ stabilized $\mathrm{cZrO}_{2}$ determined experimentally using neutron powder diffraction [23]. All the computed thermodynamics properties of $\mathrm{cZrO}_{2}$ indicates it has less thermal conductivity despite having high ionic conductivity thus confirming its major characteristic as a refractory material.

\section{Conclusion}

Using the first principles calculations, the properties of $\mathrm{cZrO}_{2}$ were investigated. The calculated lattice parameters showed conformity with available experimental data. The computed properties based on elastic constants

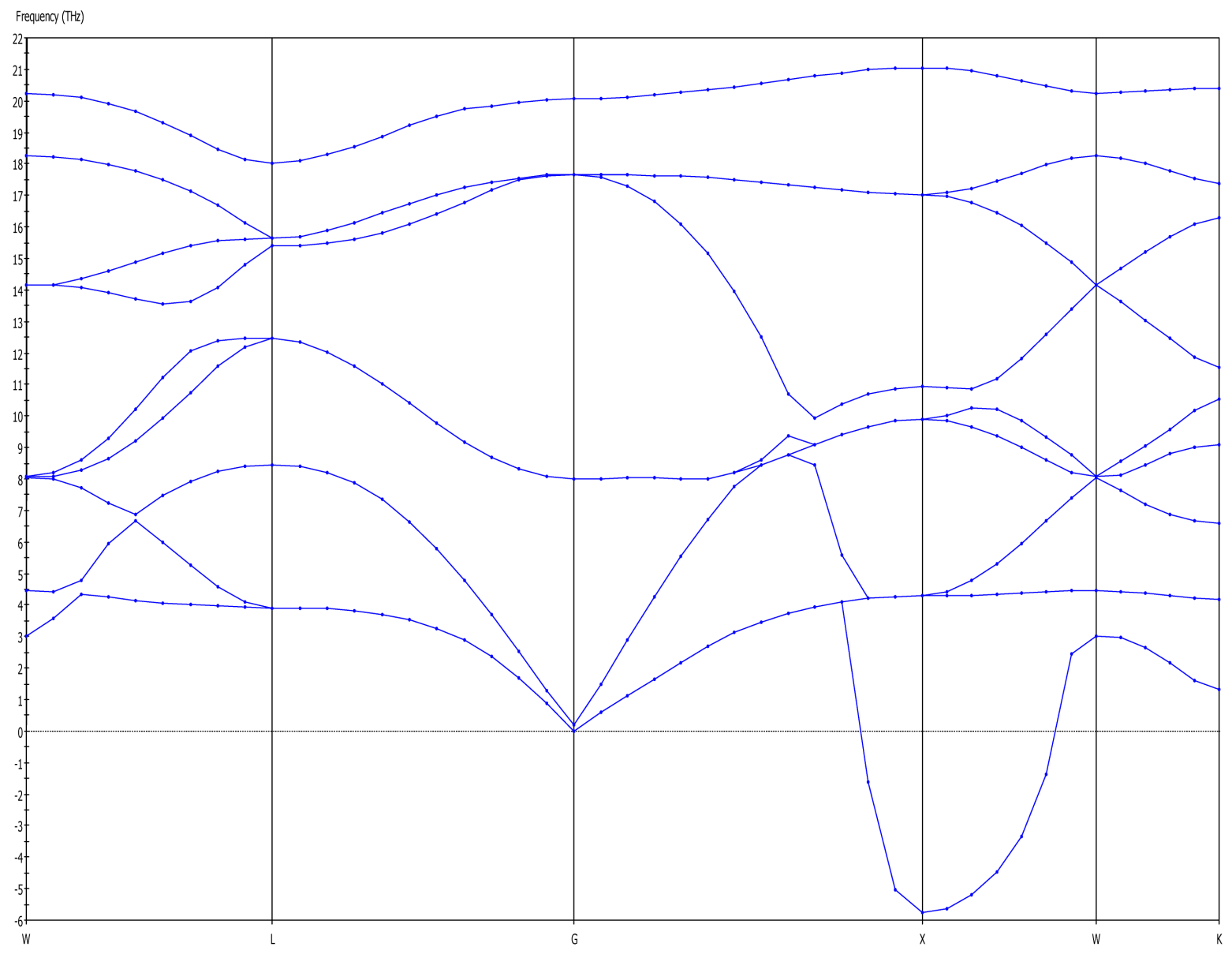

Figure 2. Phonon dispersion curves of $\mathrm{CZrO}_{2}$. 

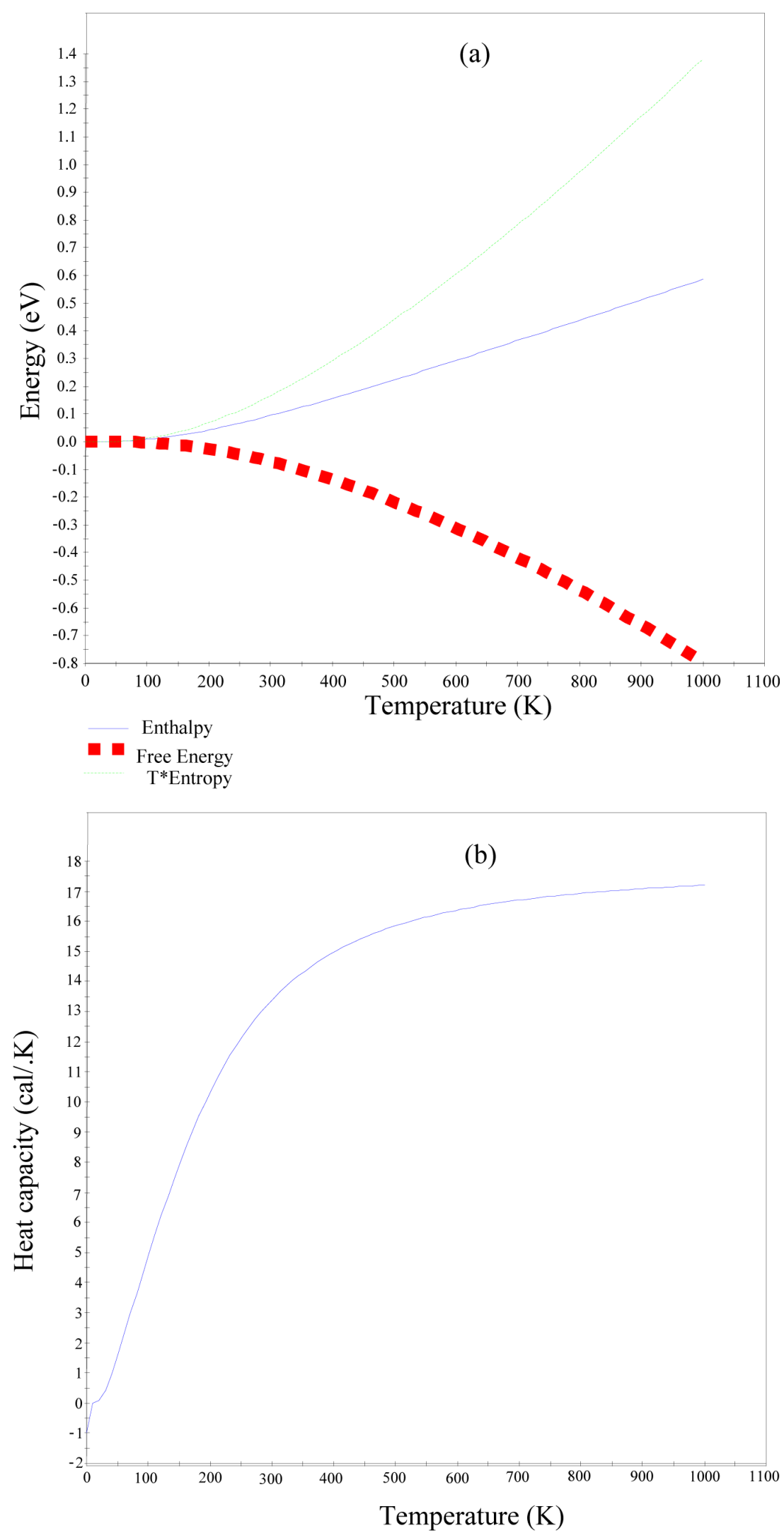

Figure 3. Enthalpy, free energy and entropy (a) and heat capacity of $\mathrm{cZrO}_{2}$. 


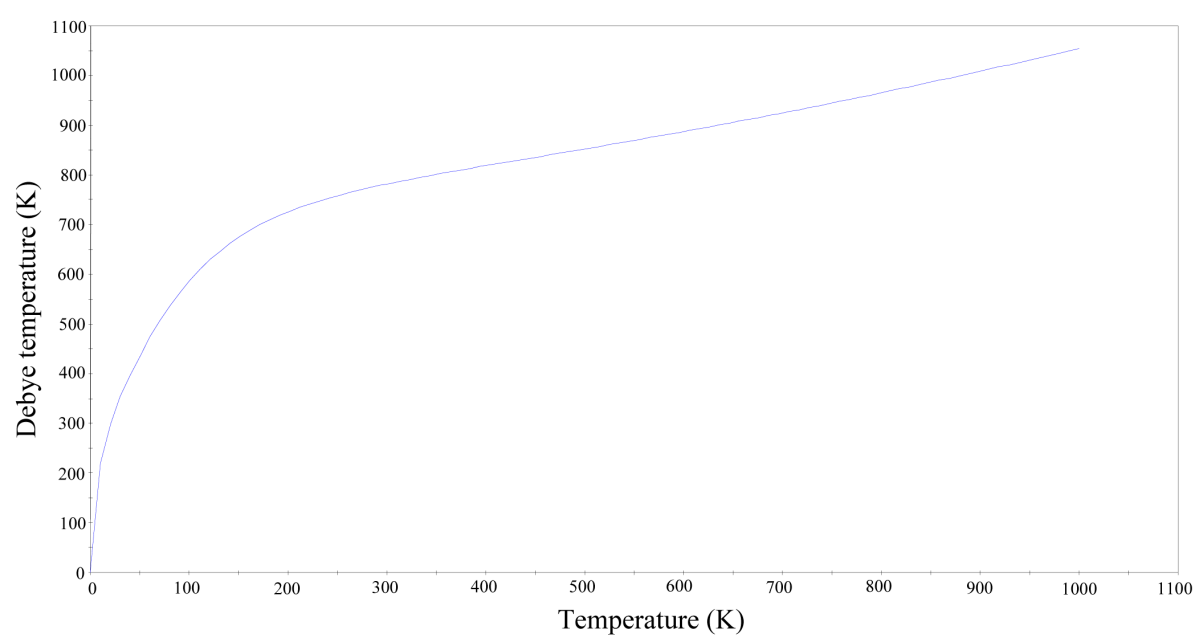

Figure 4. Debye temperature graph of $\mathrm{cZrO}_{2}$.

indicate that $\mathrm{cZrO}_{2}$ has satisfied the mechanical stability requirements; however, the young's modulus and hardness are high when compared to similar material such as cerium oxide. As expected, the thermodynamic properties obtained confirmed the ceramic characteristics of $\mathrm{cZrO}_{2}$. The data obtained may further be used to predict properties in relation to defects and/or dopants and setting parameters for processing nanocomposites related to $\mathrm{CrO}_{2}$.

\section{Acknowledgements}

The authors are grateful for the supports provided by Universiti Teknologi Petronas and Malaysian Ministry of Higher Education (MOHE) through the Long Term Research Grant Scheme (LRGS) for One Baja Research Programme (Project 6).

\section{References}

[1] Xia, X., Oldman, R. and Catlow, R. (2009) Computational Modeling Study of Bulk and Surface of Yttria-Stabilized Cubic Zirconia. Chemistry of Materials, 21, 3576-3585. http://dx.doi.org/10.1021/cm900417g

[2] Bandura, A.V. and Evarestov, R.A. (2012) Ab Initio Structure Modeling of $\mathrm{ZrO}_{2}$ Nanosheets and Single-Wall Nanotubes. Computational Materials Science, 65, 395-405. http://dx.doi.org/10.1016/j.commatsci.2012.08.001

[3] Wang, C. (2009) Multiscale Modeling and Simulation of Nanocrystalline Zirconium Oxide. Ph.D. Thesis, University of Nebraska at Lincoln.

[4] Muhammad, I.D. and Awang, M. (2013) Modelling the Interatomic Potential of Cubic Zirconia. Applied Mechanics and Materials, 446-447, 151-157. http://dx.doi.org/10.4028/www.scientific.net/AMM.446-447.151

[5] Suciu, C., Gagea, L., Hoffmann, A.C. and Mocean, M. (2006) Sol-Gel Production of Zirconia Nanoparticles with a New Organic Precursor. Chemical Engineering Science, 61, 7831-7835. http://dx.doi.org/10.1016/j.ces.2006.09.006

[6] Takenaka, S., Uwai, S., Ida, S., Matsune, H. and Kishida, M. (2013) Bottom-Up Synthesis of Titania and Zirconia Nanosheets and Their Composites with Graphene. Chemistry Letters, 42, 1188-1190. http://dx.doi.org/10.1246/cl.130587

[7] Kulkova, S., Bakulin, A., Hocker, S. and Schmauder, S. (2012) Ab-Initio Study of Metal-Zirconia Interfaces. Materials Science and Engineering, 38, 012004. http://dx.doi.org/10.1088/1757-899X/38/1/012004

[8] Lamperti, A., Cianci, E., Ciprian, R., Sangalli, D. and Debernardi, A. (2013) Stabilization of Tetragonal/Cubic Phase in Fe Doped Zirconia Grown by Atomic Layer Deposition. Thin Solid Films, 533, 83-87. http://dx.doi.org/10.1016/j.tsf.2012.11.127

[9] Welberry, T.R., Withers, R.L., Thompson, J.G. and Butler, B.D. (1992) Diffuse Scattering in Yttria-Stabilized Cubic Zirconia. Journal of Solid State Chemistry, 100, 71-89. http://dx.doi.org/10.1016/0022-4596(92)90157-Q

[10] Hou, Z.F. (2008) Ab Initio Calculations of Elastic Modulus and Electronic Structures of Cubic CaZrO 3 . Physical B: Condensed Matter, 403, 2624-2628. http://dx.doi.org/10.1016/j.physb.2008.01.025

[11] Zhang, P., Lu, Y., He, C. and Zhang, P. (2011) First-Principles Study of the Incorporation and Diffusion of Helium in Cubic Zirconia. Journal of Nuclear Materials, 418, 143-151. http://dx.doi.org/10.1016/j.jnucmat.2011.06.025 
[12] Zhao, X., Shang, S., Liu, Z. and Shen, J. (2011) Elastic Properties of Cubic, Tetragonal and Monoclinic $\mathrm{ZrO}_{2}$ from First-Principle’s Calculations. Journal of Nuclear Materials, 415, 13-17. http://dx.doi.org/10.1016/j.jnucmat.2011.05.016

[13] Miller, S.P., Dunlap, B.I. and Fleischer, A.S. (2012) Cation Coordination and Interstitial Oxygen Occupancy in Co-Doped Zirconia from First Principles. Solid State Ionics, 227, 66-72. http://dx.doi.org/10.1016/j.ssi.2012.07.017

[14] Accelrys Software Inc., San Diego (2012) Materials Studio. http://accelrys.com/products/materials-studio/index.html

[15] Clark, S.J., Segall, M.D., Pickard, C.J., Hasnip, P.J., Probert, M.J., Refson, K. and Payne, M.C. (2005) First Principles Methods Using CASTEP. Zeitschrift Fuer Kristallographie, 220, 567-570.

[16] Perdew, J.P., Burke, K. and Ernzerhof, M. (1996) Generalized Gradient Approximation Made Simple. Physical Review Letters, 77, 3865-3868. http://dx.doi.org/10.1103/PhysRevLett.77.3865

[17] Soo, Y.L., Chen, P.J., Huang, S.H., Shiu, T.J., Tsai, T.Y., Chow, Y.H., et al. (2008) Local Structures Surrounding Zr in Nanostructurally Stabilized Cubic Zirconia: Structural Origin of Phase Stability. Faculty Publications-Chemistry Department, Paper 18. http://digitalcommons.unl.edu/chemfacpub/18

[18] Chang, Y., Wang, H., Zhu, Q., Luo, P. and Dong, S. (2013) Theoretical Calculation and Analysis of $\mathrm{ZrO}_{2} \mathrm{Spherical}$ Nanometer Powders. Journal of Advanced Ceramics, 2, 21-25. http://dx.doi.org/10.1007/s40145-013-0036-2

[19] Goldsby, J.C. (2013) Basic Elastic Properties Predictions of Cubic Cerium Oxide Using First-Principles Methods. Journal of Ceramics, 2013, Article ID: 323018. http://dx.doi.org/10.1155/2013/323018

[20] Yang, Z.-J., Guo, Y.-D., Linghu, R.-F. and Yang, X.-D. (2012) First-Principles Calculation of the Lattice, Compressibility, Elastic Anisotropy and Thermodynamic Stability of $\mathrm{V}_{2} \mathrm{GeC}$, China Physics B, 21, 036301 http://dx.doi.org/10.1088/1674-1056/21/3/036301

[21] Tian, Y., Xu, B. and Zhao, Z. (2012) Microscopic Theory of Hardness and Design of Novel Superhard Crystals. International Journal of Refractory Metals and Hard Materials, 33, 93-106. http://dx.doi.org/10.1016/j.ijrmhm.2012.02.021

[22] Chong, X., Jiang, Y., Zhou, R. and Feng, J. (2014) First Principles Study the Stability, Mechanical and Electronic Properties of Manganese Carbides. Computational Materials Science, 87, $19-25$. http://dx.doi.org/10.1016/j.commatsci.2014.01.054

[23] Kisi, E. and Yuxiang, M. (2003) Debye Temperature, Anharmonic Thermal Motion and Oxygen Non-Stoichiometry in Yttria Stabilized Cubic Zirconia. Journal of Physics: Condensed Matter, 10, 3823-3832. http://dx.doi.org/10.1088/0953-8984/10/17/013 
Scientific Research Publishing (SCIRP) is one of the largest Open Access journal publishers. It is currently publishing more than 200 open access, online, peer-reviewed journals covering a wide range of academic disciplines. SCIRP serves the worldwide academic communities and contributes to the progress and application of science with its publication.

Other selected journals from SCIRP are listed as below. Submit your manuscript to us via either submit@scirp.org or Online Submission Portal.
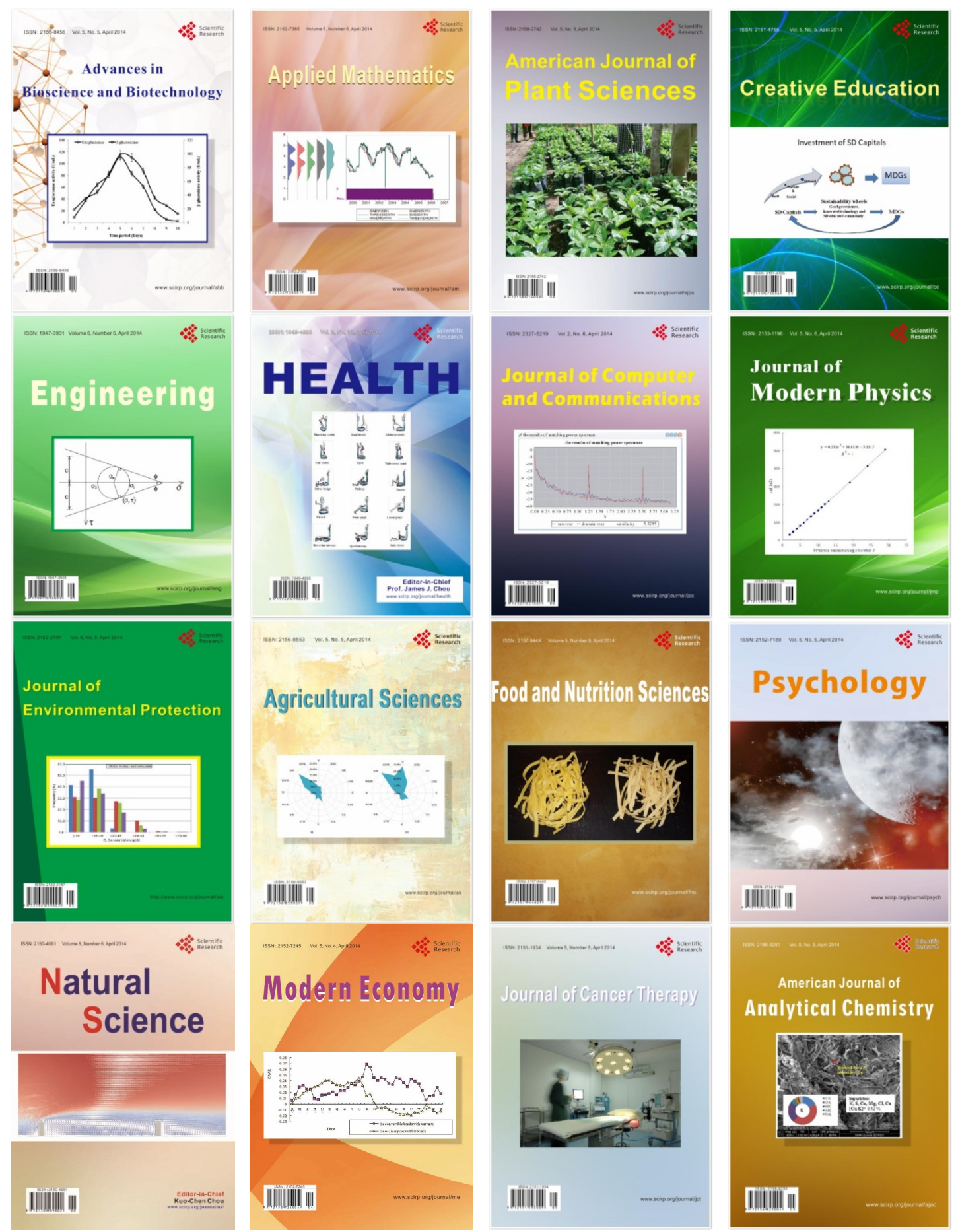